\title{
Review
}

Neonatology

\section{Oral Propranolol: A New Treatment for Infants with Retinopathy of Prematurity?}

\author{
Christoph Bührer ${ }^{\mathrm{a}}$ Dirk Bassler ${ }^{\mathrm{b}}$

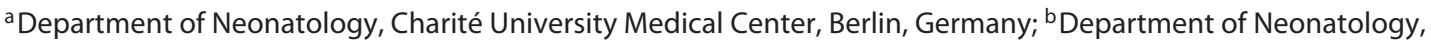 \\ University Hospital Zurich, Zurich, Switzerland
}

\section{Key Words}

Retinopathy of prematurity · Propranolol $\cdot$ Infantile hemangioma

\begin{abstract}
Introduction: Oral propranolol has improved the treatment of infantile hemangiomas, and a pediatric oral solution of propranolol has recently been licensed in the USA and Europe. In very preterm infants, infantile hemangiomas are associated with the occurrence of retinopathy of prematurity (ROP), and both diseases share a peculiar time course, featuring a lag phase after birth followed by rapid growth and then gradual regression. Objectives: To identify clinical studies evaluating the use of oral propranolol in preterm infants with ROP. Results: Two small bicentric, pilot, randomized controlled trials found a nonsignificant reduction of ROP requiring intervention by laser treatment or bevacizumab injection of similar magnitude. Together, 6 of 35 (17\%) infants who had been receiving oral propranolol underwent ROP intervention, as opposed to 14 of 36 (39\%) controls (relative risk $0.42,95 \% \mathrm{Cl}$ : 0.15-1.16). Randomized controlled trials are ongoing that investigate early preventive oral propranolol starting at 1 week of age and propranolol eye drops in preterm infants with stage 2 ROP. Conclusion: Further, large
\end{abstract}

interventional studies are required to determine the clinical benefit-risk ratio of oral propranolol to prevent vision-threatening ROP in very preterm infants.

(c) 2015 S. Karger AG, Basel

\section{Introduction}

The medical use of the $\beta$-adrenergic inhibitor propranolol in humans started over 50 years ago [1] and led to the award of the Nobel prize for medicine and physiology to its developer, the Scottish physician and pharmacologist James W. Black, in 1988. Propranolol is on the World Health Organization's list of essential medicines and is widely used in adult patients, children, and infants. Its long-standing pediatric indications include prevention of paroxysmal supraventricular tachycardia, prevention of sudden ventricular fibrillation in long QT syndrome, prevention of blue spells in tetralogy of Fallot, and treatment of hypertension in children with renal or cardiovascular disease. The serendipitous discovery of regression of infantile hemangiomas in infants treated with oral propranolol for hypertrophic cardiomyopathy in 2007 [2], followed by over 30 open-label trials [3] and two placebocontrolled trials $[4,5]$, has led to the approval of an oral

\section{KARGER 125}

(c) 2015 S. Karger AG, Base

1661-7800/15/1081-0049\$39.50/0

E-Mail karger@karger.com

www.karger.com/neo
Christoph Bührer

Klinik für Neonatologie

Charité Universitätsmedizin Berlin

DE-13344 Berlin (Germany)

E-Mail christoph.buehrer@ charite.de 
propranolol solution for the treatment of infantile hemangioma by the Federal Drug Administration in the USA, a Paediatric Use Marketing Authorization by the European Medicines Agency, and SwissMedic approval in 2014.

\section{Safety and Pharmacokinetics}

The use of oral propranolol is well established in the treatment of congenital thyrotoxicosis, and it is given prophylactically over extended periods of time to neonates with paroxysmal supraventricular tachycardia, long QT syndrome, or tetralogy of Fallot. Reported side effects of oral propranolol in infants include diarrhea, bronchitis, insomnia, nightmares, bradycardia, hypotension, and hypoglycemia [6], and in rare cases hyperkalemia upon commencement of propranolol $[7,8]$. In a study specifically reporting on treatment of very low birth weight infants with oral propranolol for infantile hemangiomas [9], no side effects were noted, but the overall number of preterm infants included was small $(n=9)$. A pharmacokinetic study of oral propranolol in term and preterm infants receiving total daily dosages of $2 \mathrm{mg} / \mathrm{kg}$ [10] demonstrated lower elimination half-lives of propranolol and apparent total body clearances than those reported in adults. However, maximal, minimal, and average concentrations, times of maximal concentration, and areas under the time-concentration curves were similar to those observed in adults when evaluated at steady state, without differences between newborns with different gestational ages or between girls and boys.

\section{Infantile Hemangioma and Retinopathy of Prematurity}

The mechanism of action by which propranolol affects the growth of infantile hemangiomas and leads to their regression is poorly understood. Infantile hemangiomas are characterized by a peculiar natural course. They start to become apparent at 1-2 months of age, display a period of rapid growth peaking at 3-5 months of age, and show gradual involution thereafter $[11,12]$. This pattern is reminiscent of the natural history of retinopathy of prematurity (ROP) which is absent during the first 4-6 weeks of life, followed by a phase of rapid vessel proliferation and sequential gradual resolution $[13,14]$. Infantile hemangiomas are more common in very preterm infants, as opposed to term infants, and there is an association between infantile hemangioma and ROP [15]. The clinical similarities of infantile hemangioma and ROP and the successful treatment of infantile hemangiomas with oral propranolol have prompted experiments with various mouse strains investigating the effects of propranolol on oxygen-induced retinopathy which bears many hallmarks of ROP. In C57Bl/6J mice, systemic propranolol reduced retinal neovascularization and reduced production of vascular endothelial growth factor (VEGF) in hypoxic retinas, without affecting VEGF production in normoxic retinas or other organs [16]. In contrast, propranolol failed to suppress retinal neovascularization in the same model when using 129S6 mice [17], which differ from $\mathrm{C} 57 \mathrm{Bl} / 6 \mathrm{~J}$ mice by a dramatic upregulation of $\beta_{3^{-}}$ adrenoreceptors after return to room air.

\section{Oral Propranolol in Infants with ROP: Randomized Controlled Trials}

We searched the International Clinical Trials Registry Platform of the World Health Organization (http://apps. who.int/trialsearch/) that collects updated trial registration data sets provided by national or supranational registries and the US National Library of Medicine (http:// www.ncbi.nlm.nih.gov/pubmed) using the terms 'propranolol' and 'retinopathy of prematurity' in October 2014, and identified two completed randomized controlled trials that have published results $[18,19]$ as well as two ongoing trials.

\section{Pilot Randomized Controlled Trials with Published Results}

The bicenter trial (NCT01238471) carried out in Haifa and Jerusalem, Israel [18], randomized 20 infants with a gestational age of 24-28 weeks at birth with stage 2 or more ROP (zone II) or stage 1 ROP (zone I) to oral propranolol (starting dose: $0.5 \mathrm{mg} / \mathrm{kg} /$ day, divided in 3 doses, incrementally increased to $1.5 \mathrm{mg} / \mathrm{kg} /$ day) or placebo until hospital discharge, full retinal vascularization, or ROP intervention by laser treatment or bevacizumab injection (on average $16 \pm 7$ days). The short study report does not provide sufficient methodological details to reliably assess the risk of bias. Two of the 10 infants randomized to oral propranolol underwent ROP treatment, as opposed to 4 of the 10 control infants ( $\mathrm{p}=0.63$, relative risk 0.44 , 95\% CI: 0.11-1.78). In the oral propranolol group, 4 out of 19 eyes underwent treatment (all by laser), as opposed to 8 out of 19 eyes in the control group (laser: $n=5$, bevacizumab: $n=3$ ). No serious side effects were noted.
Bührer/Bassler 
The bicenter trial (NCT0107915/ISRCTN18523491) carried out in Firenze and Milano, Italy [19] computerrandomized 52 preterm infants with a gestational age of 23-31 weeks at birth with ROP stage 2 to oral propranolol $(2 \mathrm{mg} / \mathrm{kg} /$ day in 4 divided doses in infants 26-31 weeks' gestational age at birth; $1 \mathrm{mg} / \mathrm{kg} /$ day in 4 divided doses in infants 23-25 weeks' gestational age) or control until full retinal vascularization (on average $66 \pm 33$ days). Allocation was concealed. One infant who initially was enrolled in the treated group developed serious adverse effects from propranolol on the first day of treatment was moved into the control group. One propranolol-treated infant died 9 days after enrolment and thus presumably before reaching the endpoint, while 2 control infants died at 61 and 87 days after enrolment, with the relationship to the endpoint being unclear. Neonatologists and nurses, but not ophthalmologists and data analysts, were aware of the allocation. Four of 25 infants analyzed who received propranolol ultimately underwent ROP treatment, as opposed to 10 of 26 controls $(p=0.12)$. This amounts to a relative risk of 0.42 with a $95 \%$ CI of $0.15-1.16$ (erroneously given as $0.31-0.58$ in the manuscript). No intentionto-treat analysis was presented, and no attempt was made to evaluate the combined endpoint 'death or ROP intervention'. In the propranolol group, 8 out of 50 eyes had laser treatment, as opposed to 19 out of 52 eyes in the control group. Rescue treatment by bevacizumab was done in 3 out of 50 eyes of the propranolol group, as opposed to 7 out of 52 eyes in the control group. There was no progression to stage $4 \mathrm{ROP}$ in the propranolol group, while it was observed in 4 out of 26 infants/ 4 out of 52 eyes in the control group. Five of the 26 newborns treated with propranolol were reported to have had serious adverse effects (hypotension, bradycardia) in conjunction with episodes of sepsis, anesthesia induction, or tracheal stimulation.

These two trials are small, and they are partly marred by statistical flaws and unclear methodological issues. Moreover, they differ with respect to inclusion criteria, dose, and - most strikingly - duration of oral propranolol administration. However, the effect sizes of the trials are very similar. Combining the published data would result in 6 infants with ROP interventions out of 35 propranolol-treated infants, as opposed to 14 out of 36 control infants $(\mathrm{p}=0.055$, relative risk $0.44,95 \%$ CI: 0.19-1.02), translating to a number needed to treat of 5 . Thus, prevention of ROP progression towards threshold disease by oral propranolol remains a promising avenue of research. It is also an important one as many ROP infants treated with laser photocoagulation still have poor visual outcome due to ablation of the peripheral retina and severe myopia [20], while intravitreal injections of anti-VEGF agents such bevacizumab, ranibizumab, or pegaptanib, all of which are off-label in infants, carry a risk of late recurrences, and may aggravate retinal detachment when used in advanced stages of ROP. Of note, intravitreal bevacizumab has been reported to reduce circulating VEGF concentrations in human infants [21], while circulating VEGF did not differ between infants receiving oral propranolol or controls [19].

\section{Ongoing Trials}

An ongoing randomized placebo-controlled trial is currently recruiting preterm infants with a gestational age between 26 and 32 weeks at 1 week of chronological age to preventive treatment with oral propranolol $(1 \mathrm{mg} / \mathrm{kg} /$ day in two divided doses) or placebo until complete vascularization or 37 weeks' gestational age (CTRI/2013/ 11/004131). Propranolol eye drops are being investigated as a treatment of progressive ROP in experimental animals [22] and in a trial with preterm human infants (NCT01079715). A formal Cochrane review into the issue has been launched (S. Kämpfen, K. Jost, R. Neumann and S. Schulzke). The limited evidence available to date does not permit drawing any firm conclusions regarding the use of propranolol to treat or prevent progression of ROP, and sufficiently powered well-designed interventional trials are urgently needed.

\section{Future Research}

There are intriguing case reports of successful administration of oral propranolol to adult patients with diffuse choroidal hemangiomas displaying exudative retinal detachment [23] or with central serous choriodopathy [24]. An open-label study investigating oral propranolol in adult patients with proliferative diabetic retinopathy and neovascularization has started recruitment. Until now, therapies for proliferative retinopathies are based on local interventions, and exploring the possibilities of systemically administered drugs has become an exciting area of research. Hopefully, it will also lead to improved longterm outcome of infants with ROP.

\section{Disclosure Statement}

The authors report no conflicts of interest. 


\section{References}

$>1$ Black JW, Crowther AF, Shanks RG, Smith LH, Dornhorst AC: A new adrenergic betareceptor antagonist. Lancet 1964;1:1080-1081.

-2 Léauté-Labrèze C, Dumas de la Roque E, Hubiche T, Boralevi F, Thambo JB, Taïeb A: Propranolol for severe hemangiomas of infancy. N Engl J Med 2008;358:2649-2651.

>3 Lou Y, Peng WJ, Cao Y, Cao DS, Xie J, Li HH: The effectiveness of propranolol in treating infantile haemangiomas: a meta-analysis including 35 studies. Br J Clin Pharmacol 2014; 78:44-57.

4 Hogeling M, Adams S, Wargon O: A randomized controlled trial of propranolol for infantile hemangiomas. Pediatrics 2011;128:e259e266.

5 Leauté-Labrèze C, Dumas de la Roque E, Nacka F, Abouelfath A, Grenier N, Rebola M, Ezzedine K, Moore N: Double-blind randomized pilot trial evaluating the efficacy of oral propranolol on infantile haemangiomas in infants $<4$ months of age. Br J Dermatol 2013; 169:181-183.

6 Goelz R, Poets CF: Incidence and treatment of infantile haemangioma in preterm infants. Arch Dis Child Fetal Neonatal Ed 2015;100: F85-F91.

7 Pavlaković H, Kietz S, Lauerer P, Zutt M, Lakomek M: Hyperkalemia complicating propranolol treatment of an infantile hemangioma. Pediatrics 2010;126:e1589-e1593.

-8 Belen B, Oguz A, Okur A, Dalgic B: A complication to be aware of: hyperkalaemia following propranolol therapy for an infant with intestinal haemangiomatozis. BMJ Case Rep 2014;2014:pii:bcr2014203.

>9 Erbay A, Sarialioglu F, Malbora B, Yildirim SV, Varan B, Tarcan A, Gulcan H, Demir S, Derbent M, Uslu N, Abbasoglu A: Propranolol for infantile hemangiomas: a preliminary report on efficacy and safety in very low birth weight infants. Turk J Pediatr 2010;52:450 456
10 Filippi L, Cavallaro G, Fiorini P, Malvagia S, Della Bona ML, Giocaliere E, Bagnoli P, Dal Monte M, Mosca F, Donzelli G, la Marca G: Propranolol concentrations after oral administration in term and preterm neonates. J Matern Fetal Neonatal Med 2013;26:833-840.

11 Chang LC, Haggstrom AN, Drolet BA, Baselga E, Chamlin SL, Garzon MC, Horii KA, Lucky AW, Mancini AJ, Metry DW, Nopper AJ, Frieden IJ: Growth characteristics of infantile hemangiomas: implications for management. Pediatrics 2008;122:360-367.

12 Chen TS, Eichenfield LF, Friedlander SF: Infantile hemangiomas: an update on pathogenesis and therapy. Pediatrics 2013;131:99-108.

-13 Palmer EA, Flynn JT, Hardy RJ, Phelps DL, Phillips CL, Schaffer DB, Tung B: Incidence and early course of retinopathy of prematurity. The Cryotherapy for Retinopathy of Prematurity Cooperative Group. Ophthalmology 1991;98:1628-1640.

14 Good WV, Hardy RJ, Dobson V, Palmer EA, Phelps DL, Quintos M, Tung B: The incidence and course of retinopathy of prematurity: findings from the early treatment for retinopathy of prematurity study. Pediatrics 2005; 116:15-23.

15 Praveen V, Vidavalur R, Rosenkrantz TS, Hussain N: Infantile hemangiomas and retinopathy of prematurity: possible association. Pediatrics 2009; 123:e484-e489.

16 Ristori C, Filippi L, Dal Monte M, Martini D, Cammalleri M, Fortunato P, la Marca G, Fiorini P, Bagnoli P: Role of the adrenergic system in a mouse model of oxygen-induced retinopathy: antiangiogenic effects of betaadrenoreceptor blockade. Invest Ophthalmol Vis Sci 2011;52:155-170.

17 Chen J, Joyal JS, Hatton CJ, Juan AM, Pei DT, Hurst CG, Xu D, Stahl A, Hellström A, Smith LE: Propranolol inhibition of beta-adrenergic receptor does not suppress pathologic neovascularization in oxygen-induced retinopathy. Invest Ophthalmol Vis Sci 2012;53:29682977.
18 Makhoul IR, Peleg O, Miller B, Bar-Oz B, Kochavi O, Mechoulam H, Mezer E, Ulanovsky I, Smolkin T, Yahalom C, Khoury A, Lorber A, Nir A, Blazer S: Oral propranolol versus placebo for retinopathy of prematurity: a pilot, randomised, double-blind prospective study. Arch Dis Child 2013;98:565-567.

19 Filippi L, Cavallaro G, Bagnoli P, Dal Monte M, Fiorini P, Donzelli G, Tinelli F, Araimo G, Cristofori G, la Marca G, Della Bona ML, La Torre A, Fortunato P, Furlanetto S, Osnaghi S, Mosca F: Oral propranolol for retinopathy of prematurity: risks, safety concerns, and perspectives. J Pediatr 2013;163:1570-1577.

20 Geloneck MM, Chuang AZ, Clark WL, Hunt MG, Norman AA, Packwood EA, Tawansy KA, Mintz-Hittner HA; BEAT-ROP Cooperative Group: Refractive outcomes following bevacizumab monotherapy compared with conventional laser treatment: a randomized clinical trial. JAMA Ophthalmol 2014;132: 1327-1333.

21 Sato T, Wada K, Arahori H, Kuno N, Imoto K, Iwahashi-Shima C, Kusaka S: Serum concentrations of bevacizumab (avastin) and vascular endothelial growth factor in infants with retinopathy of prematurity. Am J Ophthalmol 2012;153:327-333.e1.

22 Dal Monte M, Casini G, la Marca G, Isacchi B, Filippi L, Bagnoli P: Eye drop propranolol administration promotes the recovery of oxygen-induced retinopathy in mice. Exp Eye Res 2013;111:27-35.

23 Arevalo JF, Arias JD, Serrano MA: Oral propranolol for exudative retinal detachment in diffuse choroidal hemangioma. Arch Ophthalmol 2011;129:1373-1375.

24 Tatham A, Macfarlane A: The use of propranolol to treat central serous chorioretinopathy: an evaluation by serial OCT. J Ocul Pharmacol Ther 2006;22:145-149. 